\title{
10 ANOS DE PESQUISA DA REVISTA BRASILEIRA DE INOVAÇÃO SOB A ÓTICA DA BIBLIOMETRIA \\ E DA REDE SOCIAL
}

\author{
10 YEARS OF RESEARCH BY THE BRAZILIAN \\ JOURNAL OF INNOVATION, FROM THE PERSPECTIVES OF \\ BIBLIOMETRICS AND SOCIAL NETWORKING
}

Recebido em: 12/04/2014 - Aprovado em: 27/06/2014

Avaliado pelo sistema double blind review Editora Científica: Manolita Correia Lima

\section{HENRIQUE CÉSAR MELO RIBEIRO hcmribeiro@hotmail.com UNIVERSIDADE NOVE DE JULHO}

\section{ROSANY CORRÊA}

UNIVERSIDADE ESTADUAL DO PIAUÍ

\section{RESUMO}

Este artigo explorou a produção científica da Revista Brasileira de Inovação no período de 2002 a 201 I. A referida pesquisa se norteou numa pesquisa bibliométrica e de rede social, utilizando-se de estatística descritiva em Ioo artigos identificados. Os principais resultados foram: a prevalência de parcerias de dois a sete autores; verificou-se a baixa integração entre os autores, impactando na densidade da rede dos pesquisadores e, consequentemente, de suas respectivas IES. A Universidade Federal do Rio de Janeiro (UFRJ), Universidade Estadual de Campinas (Unicamp) e Universidade Federal de Minas Gerais (UFMG), são as IES mais centrais deste estudo; constatou-se um equilíbrio entre as abordagens qualitativa e quantitativa. Também uma predominância nos tipos de pesquisa documental e bibliográfica. E o estudo de caso como um dos métodos de estudo mais visto nos roo artigos investigados; e as áreas de estudo que se destacaram foram: políticas de ciência, tecnologia e inovação, gestão da inovação e mudança tecnológica e organizacional, representando $53 \%$ do montante de todas as áreas.

Palavras-chave: Revista Brasileira de Inovação; bibliometria; rede social; Ensino e Pesquisa; inovação.

\footnotetext{
ABSTRACT

This paper explores the scientific production of the Brazilian Journal of Innovation for the period 2002 to 2011. The research was organized using bibliometric and social networking research methods on the descriptive statistics identified in 100 papers. The main results were a prevalence of partnerships comprising two to seven authors with low integration between authors, impacting the density of the networks of researchers and, consequently, their respective HEIs. The UFRJ, Unicamp and UFMG were the moat central HEIs in this study and a balance was found between qualitative and quantitative approaches. There was also a predominance of documentary and literature research, while the case study was one of the most common approaches in the 100 papers investigated. The areas of study that stood out were: political science, technology and innovation, management innovation and technological and organizational change, which accounted for $53 \%$ of the total.

Keywords: Brazilian Journal of Innovation; bibliometrics; social network; learning and research; innovation.
} 


\section{INTRODUÇÃO}

Nas ultimas décadas os processos de inovação tecnológica vem ocupando lugar central na competitividade entre países que atuam em um cenário globalizado (A MORIM-BORHER et al., 2007), sendo que, cada vez mais estudados em: setores distintos, comparações nacionais e internacionais, indicadores de inovação, pesquisa e desenvolvimento, por meio de várias abordagens teóricas, fomentando a publicação em nível nacional e internacional. Tal fato remete que, na sociedade do conhecimento, o elemento diferenciador na atividade produtiva é o próprio conhecimento (CALLE; SILVA, 2008).

A criação de revistas em áreas específicas, como é o caso da Revista Brasileira de Inovação (RBI), criada em 2002, vem consolidar a área de inovação. A RBI tem o propósito de servir ao debate acadêmico e institucional sobre a inovação, contribuindo para o avanço da ciência brasileira e para o desenvolvimento nacional (RBI, 20I2).

Neste panorama, a técnica da bibliometria, que é o estudo dos aspectos quantitativos da produção, disseminação e uso da informação registrada (MACIAS-CHAPULA, 1998) e a rede social, que é uma representação das relações e interações entre atores de um grupo, tendo papel preponderante na disseminação de informações, ideias e influências (KIMURA; BASSO; MARTIN, 2008), fomentando, assim, o desenvolvimento de inovações (TOMAÉL; ALCARÁ; DI CHIARA, 2005).

Ao se definir a Revista Brasileira de Inovação como objeto de estudo, usou-se as técnicas da bibliometria e da rede social, para explorar a produção científica desta revista no período de dez anos.

Diante disso, a pergunta de pesquisa que orientou este trabalho é: Qual é a representação das pesquisas científicas da Revista Brasileira de Inovação no período de 2002 a 20II? Tal questionamento foi respondido mediante os seguintes indicadores: (I) autoria; (II) autores mais prolíferos; (III) redes de coautoria; (IV) referências mais citadas; (V) IES mais profícuas; (VI) rede das IES; (VII) abordagens metodológicas; (VIII) frequência de palavras-chave; e (IX) áreas de estudo. O objetivo desta pesquisa se delineou sendo: explorar a produção científica da Revista Brasileira de Inovação no período de 2002 a 201 I. 
Este artigo está disposto em cinco partes. A primeira descreve a introdução, com a justificativa, pergunta e o objetivo da pesquisa. $\mathrm{O}$ referencial teórico é evidenciado na parte dois. Depois são contemplados os procedimentos metodológicos usados na pesquisa. A quarta parte aborda a análise dos resultados. Por fim, na última parte são evidenciadas as discussões e considerações finais, limitações da pesquisa e as recomendações para estudos futuros. 


\section{REFERENCIAL TEÓRICO}

Nesta seção, são descritos os principais eixos dos debates, apresentados nos estudos acerca de análise bibliométrica e de rede social; e sobre inovação tecnológica.

\section{INOVAÇÃO TECNOLÓGICA}

A inovação é um processo contínuo nas empresas que buscam, de forma sistêmica, melhorias em produtos e processos, com o objetivo de aumentar sua participação no mercado. Cassiolato, Brito e Vargas (2005, p. 513) afirmam que: "[...] a inovação é cada vez mais entendida como sendo um processo que resulta de complexas interações em nível local, nacional e mundial entre indivíduos, firmas e outras organizações voltadas à busca de novos conhecimentos".

Quando uma inovação é introduzida pioneiramente por uma única empresa, seus impactos econômicos são limitados ao âmbito do inovador e, eventualmente, de seus clientes (TIGRE, 2006). Nelson (2006) distingue três classes de meios em que as firmas podem colher retornos a suas inovações - por meio do sistema de patentes, por meio do segredo, e por meio de diversos benefícios associados à exploração das vantagens do pioneirismo.

Para Tidd, Bessant e Pavitt (2008) a inovação é movida pela habilidade de estabelecer relações, tirar proveito delas e detectar oportunidade. Consiste não apenas na abertura de novos mercados, mas também nas formas novas de atender a mercados já estabelecidos e maduros.

Freeman e Soete (2008) consideram que há várias estratégias alternativas que as firmas podem seguir. No entanto, dependendo de seus recursos, sua história, suas atitudes de gestão e sua sorte, as mudanças na tecnologia e no mercado e os avanços feitos pelos concorrentes podem impedi-las de tentar e de manter o ritmo, de uma forma ou de outra.

O processo de geração de inovação contempla um horizonte mais amplo, envolvendo difusão, absorção e aperfeiçoamento de tecnologias para a aplicação na atividade produtiva (MARION FILHO; SONAGLIO, 20IO). Cabe às 
empresas adotar, adaptar, ampliar e transformar tecnologias num processo de acumulação e de resultados inovadores, em processos e produtos.

A apresentação do Manual de Oslo, já em sua terceira versão, define quatro áreas de inovações que encerram um amplo conjunto de mudanças nas atividades das empresas: inovações de produto, de processo, organizacionais e de marketing (OCDE, 2005). Segundo Tidd, Bessant e Pavitt (2008), os tipos de inovação se centram em quatro categorias chamadas de 4 Ps da inovação, sendo: inovação de produto; processo; posição e paradigma.

A literatura sugere que o comportamento inovador nas empresas, inicialmente, se define por setores. Uma abordagem tradicional para analisar o ritmo e a direção da mudança tecnológica setorial é a que estabelece padrões de comportamento inovador entre firmas que, incluindo aquelas pertencentes a diferentes setores, compartilham características similares nos seus processos de inovação (RUIZ; BHAWAN, 20IO), diferenças no desempenho inovativo entre países ou setores podem resultar de diferentes graus de compatibilidade entre as tecnologias físicas e sociais (YONAMINI; GONÇALVES, 20IO).

Coriat e Dosi (2002) afirmam que as empresas têm formas de evoluir, mostrando assim, fortes elementos de continuidade, apesar de, fundamentalmente, terem maneiras distintas de fazer as coisas: as empresas são, geralmente, heterogêneas, mesmo nas formas como realizam tarefas funcionalmente semelhantes, para não falar da grande escala de diferenças que separam as empresa por setores. No contexto econômico de alta competitividade, a empresa depende de sua capacidade de inovar, com maior rapidez que a concorrência, explorando maneiras novas para desenvolver a inovação.

A OCDE (2005) pressupõe que as atividades de inovação de uma empresa dependem parcialmente da variedade e da estrutura de suas relações com as fontes de informação, conhecimento, tecnologias, práticas e recursos humanos e financeiros. Ruiz e Bhawan (2010) apontam para as características da firma (tamanho, estrutura organizacional, etc.) como importantes determinantes de aspectos dos processos de inovação, como a origem de recursos ou o aprendizado. 
Ainda segundo a OCDE (2005), na terceira edição, expande a estrutura de mensuração da inovação em três importantes sentidos. Primeiro, há uma maior ênfase no papel das interações com outras empresas e instituições no processo de inovação. Além disso, a importância de inovação é reconhecida em indústrias menos intensivas em pesquisa e desenvolvimento (P\&D), como os serviços e a indústria de transformação de baixa tecnologia. Esta edição modifica alguns aspectos da estrutura (tais como definições e atividades relevantes) para melhor acomodar o setor de serviços. Finalmente, a definição de inovação é expandida para incluir dois outros tipos de inovações: a organizacional e de marketing (OCDE, 2005).

A inovação desempenha um papel fundamental tanto para o processo de diferenciação dos agentes quanto para o crescimento econômico, e é responsável por diferenças de longo prazo do desempenho econômico (YONAMINI; GONÇALVES, 2010). Para Marion Filho e Sonaglio (20I0), eficiência no uso de tecnologias de produto, processo e gestão está diretamente relacionada à competitividade de empresas, cadeias produtivas, regiões e nações.

Ciência, tecnologia e política de inovação desempenham um papel cada vez mais importante no contexto do desenvolvimento das sociedades modernas (METCALFE, 2003). Esta ideia é corroborada por Barañano (2005), quando afirma que o progresso tecnológico leva, por meio do aumento da produtividade/competitividade das empresas, ao desenvolvimento econômico que, por sua vez, eleva o nível de vida da população em geral.

A evolução permanente dos produtos e processos vem sendo reconhecida nos anos recentes como fundamental à saúde competitiva das empresas em quase todas as indústrias (ALVES; BOMTEMPO; COUTINHO, 2005).

As empresas quanto mais inovam, mais competitivas se tornam. Ao introduzir inovação organizacional e tecnológica, fomentam o desenvolvimento e a riqueza. Segundo Tigre (2005), a competitividade de uma empresa em uma atividade particular é definida pelos evolucionistas como um conjunto de competências tecnológicas diferenciadas, de ativos complementares e de rotinas. Tais competências são geralmente tácitas e não transferíveis, conferindo à firma um caráter único e diferenciado. A competitividade entre as empresas fomenta as competências da firma e a inovação. 
O papel desempenhado pelas inovações na transformação de processos e produtos nas empresas exerce uma força inquestionável no desenvolvimento de regiões, de cidades e de nações. Para Santana, Hasenclever e Mello (2003), o desenvolvimento econômico pode ser compreendido sob a perspectiva de buscar novos rumos para a geração, organização e gerência da riqueza dos países e está, obrigatoriamente, relacionado com o processo de mudança tecnológica, que é resultado do esforço das empresas em investir em atividades de pesquisa e desenvolvimento e na incorporação posterior de seus resultados em novos produtos, processos e formas organizacionais.

A OCDE (2005), no prefácio de sua terceira edição, já prevê que a geração, exploração e a difusão do conhecimento são fundamentais para o crescimento econômico, o desenvolvimento e o bem-estar das nações, sendo fundamental dispor de melhores medidas de inovação.

A Organização para Cooperação e Desenvolvimento Econômico - OCDE (2006), em uma de suas pesquisas, afirma que as nações que desenvolvem e gerenciam efetivamente seus ativos de conhecimento têm melhor desempenho que as outras, o que corrobora com a afirmação a respeito da importância da consolidação do desenvolvimento tecnológico e da inovação.

Em seu estudo, Cimoli et al. (2007) corroboram com o processo evolutivo da inovação, quando afirmam que as novas tecnologias e, mais geralmente, as novas práticas que vão sendo incorporadas, embora sejam novas nos países que procuram emparelhar-se aos mais avançados, estão, de modo geral, bem estabelecidas nos países situados na fronteira tecnológica.

O Brasil começou a investigar a inovação por meio do Instituto Brasileiro de Geografia e Estatística (IBGE). A Pesquisa Industrial de Inovação Tecnológica (PINTEC), 2000, foi a primeira e mais abrangente investigação oficial do fenômeno da inovação tecnológica na indústria brasileira, seus indicadores serviram para ampliar o entendimento do processo de inovação na indústria nacional, promovendo a comparabilidade de dados com outros países (IBGE, 2002).

a inovação no Brasil está atrelada a busca de competências capazes de acender ganhos de produtividade, eficácia e qualidade. Muitas organizações nacionais já descobriram a importância da estratégia em inovação para o aperfeiçoamento de seus negócios (LOPES; BARBOSA, 2006). 
As pesquisas acadêmicas são preponderantes, pois, propiciam uma maior compreensão de como as áreas do conhecimento e/ou temas acadêmicos são ou estão sendo tratados e difundidos na literatura acadêmica nacional e internacional, em especial, para esta pesquisa, que foca no assunto Inovação, que apesar de algumas pesquisas bibliométricas já terem sido publicadas sobre este contexto, o referido tema não se esgotou, no que tange a elencar características que lhe são inerentes e podem ser úteis para a otimização deste tema em publicações em eventos, revistas e em grupos de pesquisas, contribuindo assim para o surgimento de novos pesquisadores para o referido campo.

\section{ESTUDOS DE ANÁLISE BIBLIOMÉTRICA E DE REDE SOCIAL SOBRE INOVAÇÃO}

Estudos realizados nas últimas décadas sobre inovação pelo método da análise bibliométrica e de redes sociais contribuem para construção de um panorama atual e a evolução ocorrida na temática ora investigada. Foi após 2003 que as publicações sobre inovação começaram a crescer em número de artigos, esse crescimento se justifica tanto pelo aumento de publicações acadêmicas de modo geral, quanto pelo maior interesse dos pesquisadores sobre o tema de inovação, influenciando suas redes de cooperação (LOPEs; CARVALHO, 20I2).

Entende-se que a análise bibliométrica permite estabelecer uma relação positiva entre pesquisa científica e a produção, nesse caso considerando a inovação como temática. Calle e Silva (2008) afirmam que a inovação sustenta-se em elementos como criatividade, mas também necessita de uma base de conhecimento prévio, principalmente tácito, e da pesquisa científica, que vai atuar com uma catalisadora para ampliar os horizontes e quebrar paradigmas estabelecidos.

Bignetti (2006) apresentou a forma como os pesquisadores têm abordado os diferentes temas sobre inovação em trabalhos apresentados nos encontros da Associação de Programas de Pós-Graduação em Administração (ANPAD). O autor observou que há predominância dos estudos que se voltam para o entendimento da dinâmica da criação 
e mobilização do conhecimento e da inovação em todos os níveis organizacionais.

Gazda e Quandt (2010) investigaram as tendências brasileiras de coautoria de artigos relacionados à gestão da inovação apresentados no Simpósio de Gestão da Inovação Tecnológica, entre 1998 e 2008. Os resultados obtidos por esses autores foram de uma alta concentração de trabalhos do eixo SulSudeste $(80 \%)$, bem como a presença da Bahia e do Distrito Federal, entre os oito estados mais produtivos. Com exceção da Bahia, os estados do Norte e Nordeste não conseguiram alcançar 3\% de participação.

Matheus, Vanz e Moura (2007) compararam indicadores brasileiros de produção científica (artigos) e de produção tecnológica (patentes), de 2000 a 2004, identificando assim a rede de colaboração e suas semelhanças e diferenças. Os principais resultados foram: o número de registros de patentes, diferentemente do número de publicações acadêmicas, não cresceu de forma consistente no período analisado; não foi encontrada uma relação positiva entre a colaboração interinstitucional no registro de patentes e o número de patentes registradas, ou seja, a instituição que mais colabora (Universidade de São Paulo - USP) não é aquela que mais registra patentes (Universidade Estadual de Campinas - Unicamp).

Considerando o marketing boca a boca, num contexto das redes sociais, os autores Kimura, Basso e Martin (2008) procuraram avaliar a difusão do uso de novas tecnologias, em razão da velocidade de surgimento de inovações. De maneira geral, os autores observaram que o fortalecimento de vínculos entre indivíduos e a implantação de programas de marketing, que explorem as interações nas redes sociais, constitui numa importante estratégia para o aumento da velocidade de difusão de tecnologias.

Muÿlder et al. (2008) apontaram a incidência do termo inovação nos artigos publicados na Associação Nacional de Pós-Graduação e Pesquisa em Administração (ANPAD) em 2007, mas concluíram que os artigos não tratam, de forma unânime, intensa ou aprofundada, sobre o assunto. Afirmaram que existe uma maior concentração de ocorrência desse tema na divisão acadêmica de gestão de ciência, tecnologia e inovação. Da mesma forma, Andrade e Muÿlder (2010) verificaram a inserção dos temas inovação e 
qualidade na área contábil, e sua evolução no meio acadêmico, concluindo que a temática inovação ainda é pouco explorada no contexto contábil.

Analogamente, a inserção e a utilização do termo inovação foram analisados por Kneipp et al. (2010) nos eventos da ANPAD de 1997 a 2009, verificando que a Universidade Federal do Rio Grande do Sul se destaca com o maior número de artigos publicados sobre o tema em questão. Rasera e Balbinot (2010) investigaram como a inovação associada a redes vem sendo abordada no Brasil. Eles constataram um crescimento de sua abordagem, especialmente, da inovação aberta, uma estabilização do tema redes de inovação e um declínio da abordagem do tema inovação em redes.

Rasera e Cherobim (2010) analisaram como o investimento em tecnologia da informação voltado à inovação vem sendo referenciado nas publicações acadêmicas nacionais. Eles notaram baixo interesse em referenciar a inovação como motivação para os investimentos em tecnologia da informação. Costa et al. (20II), por sua vez, fizeram uma análise quantitativa da produção científica publicada sobre inovação e propriedade intelectual, de 2000 a 2010. Observaram que em grande parte das revistas pesquisadas, entre as vinte mais produtivas, os temas inovação e propriedade intelectual são comumente empregados.

Já os pesquisadores Tálamo e Carvalho (2010) levantaram fatores motivadores e críticos ao sucesso da estruturação de redes de cooperação com foco em inovação em 15 empresas. Concluíram que a estruturação na forma de redes de cooperação traz resultados efetivos às empresas, dotandoas de competitividade e flexibilidade em relação aos desafios de mercado.

Kneipp et al. (20II) analisaram as publicações científicas vinculadas ao tema inovação nos anais do Encontro da Associação Nacional de PósGraduação e Pesquisa em Administração (EnANPAD) e nos periódicos, Revista de Administração Contemporânea (impressa e eletrônica) e Brazilian Administration Review, no período de 1997 a 2010. Os principais achados foram: aumento considerável das publicações entre os anos de 2006 a 2008; as IES: Universidade Federal do Rio Grande do Sul, Universidade Presbiteriana Mackenzie, Universidade Federal da Bahia, Universidade de São Paulo e Universidade de Brasília foram as que mais publicaram sobre 
o tema no período analisado; e a abordagem qualitativa é a predominante nos artigos investigados.

Usando a base do Web of Science, os autores Kneipp et al. (20II) analisaram as características das publicações sobre Sustainable Innovation, entre os anos de 2000 a 20I0. Foi observado nesta pesquisa um aumento gradual da produção científica, em especial nas seguintes áreas temáticas: gestão, ciências ambientais, negócio.

Saquetto e Carneiro (20II) analisaram quais foram às discussões promovidas sobre o tema inovação entre os anos de 200 a 20Io. Tal pesquisa foi realizada em revistas acadêmicas de conceito "A". Constataram que nos anos de 2009 e 20Io, o número de publicações relativas ao tema inovação aumentou. Apesar disso, como o número de publicações nos primeiros anos se manteve constante, tal aumento não pôde caracterizar uma tendência de crescimento futuro no número de publicações sobre o tema.

Scarpin, Gomes e Machado (20II) identificaram a formação de redes na produção científica sobre inovação, no período de 2006 a 20Io, nos periódicos Qualis Capes de alto impacto, ou seja, Ar a B2 do Brasil. Eles constataram que poucos autores publicaram muito, porém, verificaram uma cooperação entre suas respectivas Instituições de Ensino Superior - IES.

As publicações internacionais da área de inovação que tratam de conhecimento organizacional foram levantadas por Santos, Uriona-Maldonado e Santos (20II), que constataram um crescimento na quantidade de pesquisas sobre a temática, principalmente em 2009. Da mesma forma, os temas inovação e cooperação foram investigados por Lopes e Carvalho (2012), por meio de uma análise da literatura entre os anos de I99I a 20I0. Eles constataram um crescimento de ambos os temas a partir de 2000, com um pico em 2008.

Já Muÿlder (20I2) fez um estudo das publicações nos anais do principal evento nacional denominado EnANPAD, no período de 2007 a 201 , com o objetivo de identificar os artigos que tratavam de temas, tais como inovação e arranjos produtivos locais. O autor concluiu que a extração de documentos, por meio de palavras-chave em acervos que representam o lócus do saber, permite traçar tendências e sugere a exploração de termos substitutivos aos pesquisados. 
Ao se estabelecerem redes sociais entre os autores se consolida uma sociedade em rede de produção científica, de parcerias e entre instituições. A adoção de métodos de análise de redes sociais permite um nível de detalhamento e visualização que não é possível, utilizandose métodos estatísticos tradicionais (MATHEUs; VANZ; MOURA, 2007).

Machado e Machado (2012) estudaram as revistas Qualis Nacional de alto impacto ( $>$ de $\mathrm{B} 2$ ) até o ano de 20Io, em 3I artigos que tratam sobre o tema inovação junto com a temática estratégia. Concluíram que houve um aumento de produção sobre os temas e, quanto aos autores, perceberam que os pesquisadores tendem a publicar, em sua maioria, entre pares de uma mesma instituição de ensino. Isso mostra uma endogenia em termos de publicação.

Ribeiro, Cirani e Freitas (2013) investigaram a produção cientifica brasileira da Revista de Administração e Inovação, mediante a análise bibliométrica e de rede social de 2006 a 20I2, em 216 artigos identificados. Constataram que predominância de artigos publicados em parceria; a USP foi a IES que mais publicou artigos; e os temas mais publicados foram: estudos setoriais e tecnologia; organização e de negócios; redes organizacionais; gestão do conhecimento; e empreendedorismo e PMEs.

Observando os diversos estudos bibliométricos que enfatizam a inovação, constatou-se que eles realçaram vastas informações, por meio de bancos de dados de eventos, o da ANPAD foi o mais pesquisado; e de periódicos nacionais de extratos Ar a B2. Contudo, não foram identificados trabalhos que colocassem em evidencia revistas da área de Inovação especificamente que é o foco desta pesquisa.

Este estudo contribuirá para desenvolver, aperfeiçoar, socializar e evidenciar a importância do tema Inovação, sob a ótica da Revista Brasileira de Inovação. E por entender que existem poucos periódicos científicos nacionais para consulta especializada, esta pesquisa, colaborará para difundir a essência e importância que a revista em investigação tem no contexto nacional sobre o campo do conhecimento inovação, ao realçar as características: autoria, autores mais prolíferos, redes de coautoria, referências mais citadas, IEs mais profícuas, rede 
10 ANOS DE PESQUISA DA REVISTA BRASILEIRA DE INOVAÇÃO SOB A ÓTICA DA BIBLIOMETRIA E DA REDE SOCIAL

das IEs, abordagens metodológicas, frequência de palavras-chave e áreas de estudo. 


\section{PROCEDIMENTOS METODOLÓGICOS}

Este estudo tem por objetivo explorar as características da produção científica da Revista Brasileira de Inovação, no período de 2002 a 201 I. Portanto, este trabalho consiste em uma análise bibliométrica (VANTI, 2002), de natureza descritiva e explicativa (FRANCISCO, 20II). Assim, se constitui num campo de estudo que usa métodos provenientes da matemática e estatística, de modo a observar incidências e verificar a produção escrita referente a um determinado periódico.

As leis bibliométricas mais renomadas são compostas das seguintes características: (a) Lei de Bradford, que enfatiza a produtividade dos periódicos, estima-se que o grau de relevância da revista seja um aspecto bastante importante neste contexto; (b) Lei de Lotka, que destaca a produtividade científica de autores, ou seja, o número de vezes que cada autor aparece citado em outros trabalhos científicos. Neste caso, usa-se um modelo de distribuição de tamanho-frequência em um conjunto de pesquisas, que evidencia aspectos de coautoria; e (c) Leis de Zipff que conta as incidências de palavras que aparecem nos artigos científicos, como, por exemplo, as palavras-chave mais visualizadas nos artigos investigados nesta pesquisa. No contexto deste estudo, são contempladas as Leis de Lotka e Zipf.

Complementando a investigação bibliométrica, também foi utilizado um monitoramento das redes de coautoria (RAMOS-RODRÍGUEZ; RUíZ-NAVARRO, 2004) que permite compreender as ligações e conectividades entre autores e suas respectivas IES. Essa relação entre os autores e instituições fomenta a pesquisa por meio das parcerias e de publicações conjuntas.

Diante do exposto, foi realizada a busca de todos os artigos, por meio do site da própria revista. Com isso, o universo da pesquisa foi composto por Ioo artigos (Gráfico I) publicados no período 2000-20II. A revista tendo uma periodicidade semestral publicou roo artigos em I2 anos de estudos. 
Gráfico I Artigos publicados na Revista Brasileira de Inovação de 2002 a 20 II

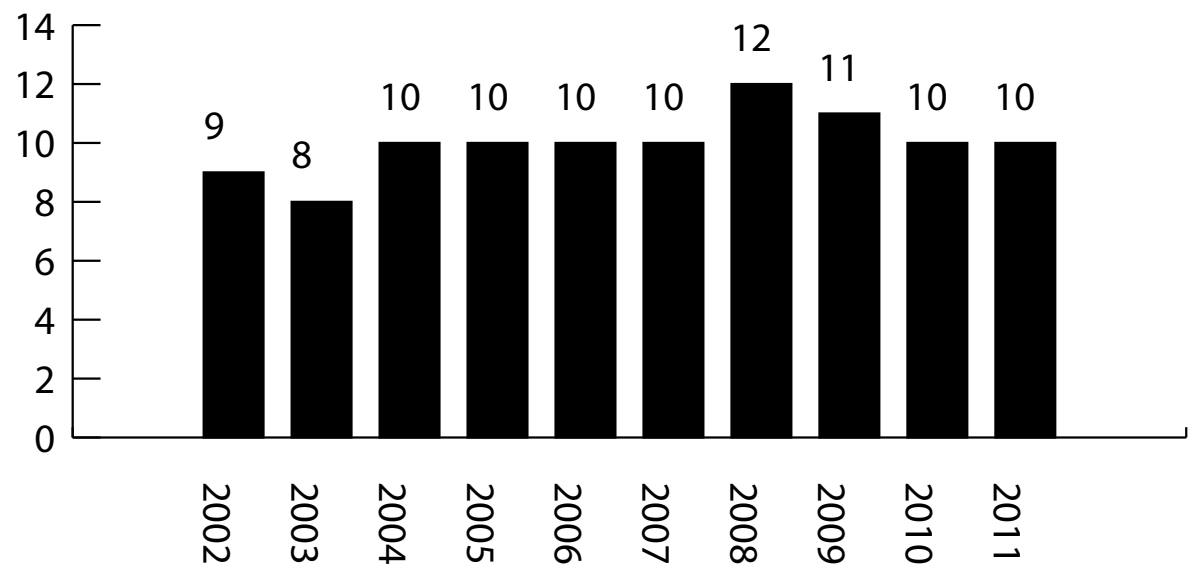

O estudo realizou a análise dos seguintes indicadores: (I) autoria; (II) autores mais prolíferos; (III) redes de coautoria; (IV) referências mais citadas; (v) IES mais profícuas; (VI) rede das IES; (VII) abordagens metodológicas; (VIII) frequência de palavras-chave; e (Ix) áreas de estudo. Portanto, este trabalho utilizou-se da abordagem quantitativa, mediante, a estatística descritiva. Para tabular, gerar as informações e, a posteriori, os gráficos, figuras e as representações das redes sociais, foram utilizados os softwares Microsoft Excel 2007, depois o UCINET 6 for Windows (versão 6.357) e o Wordle.net. 


\section{ANÁLISE DOS RESULTADOS}

A finalidade deste capítulo foi mobilizar a análise bibliométrica e de rede social dos Ioo artigos publicados na Revista Brasileira de Inovação.

\section{AUTORIA}

O Gráfico 2 apresenta a frequência de artigos de autoria individual e em parceria (dois ou mais autores) no período analisado.

Gráfico 2 Características de autoria

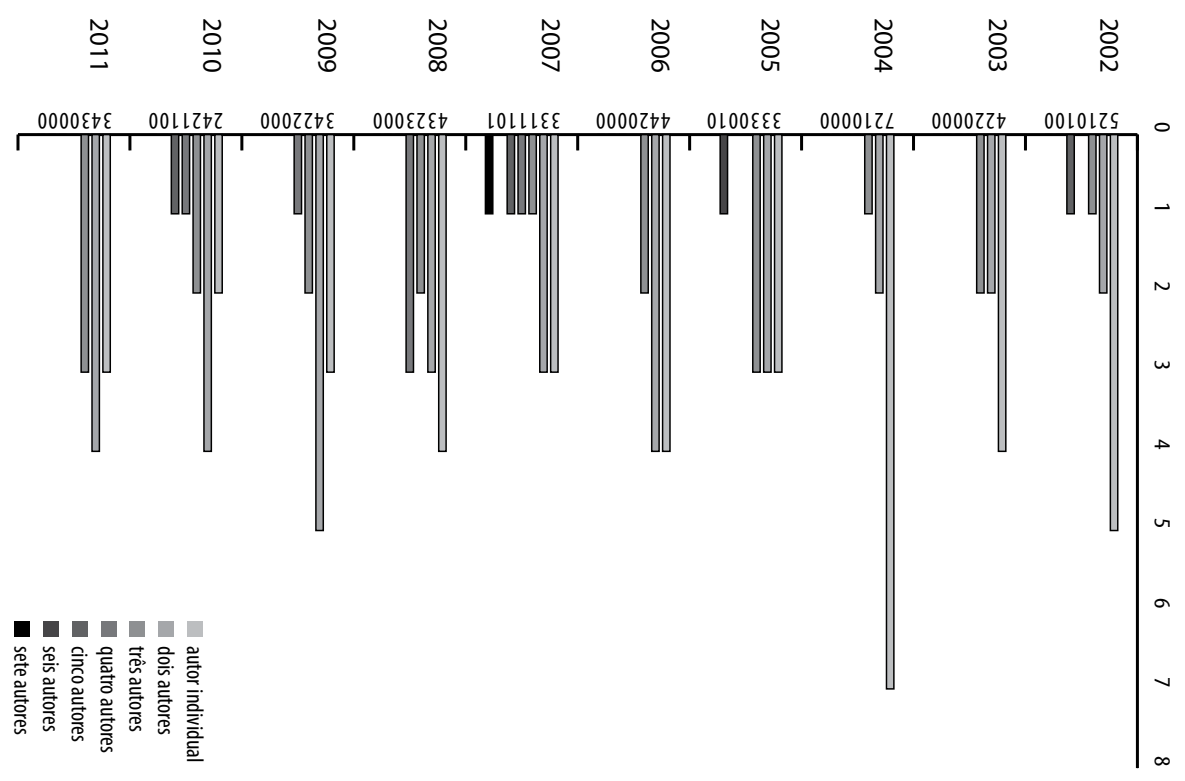

Ao analisar o Gráfico 2, percebe-se que prevalece o número de artigos publicados com dois a sete autores, representando $62 \%$ do total de roo artigos. Remete-se à média de autoria nos dez anos de pesquisa que foi, aproximadamente, 2,Io autores (Gráfico 3) por artigo publicado. Isso vem afirmar que a autoria de publicações realizada com dois ou mais autores é predominante em pesquisas acadêmicas, em especial, nesta última década, a qual realça a importância das redes de parceria, impactando no maior rendimento de publicações de autores, ocasionando também, a difusão de 
áreas, campos e/ou temas acadêmicos que porventura poderiam estar em uma fase incipiente na literatura acadêmica internacional e/ou nacional. Em suma, as parcerias são predominantes para a socialização e otimização de áreas do conhecimento, especialmente em temáticas, ocasionando a posteriori sua evolução, agregando valor ao campo o qual este assunto esta vinculado.

Gráfico 3 Média de autores por artigo

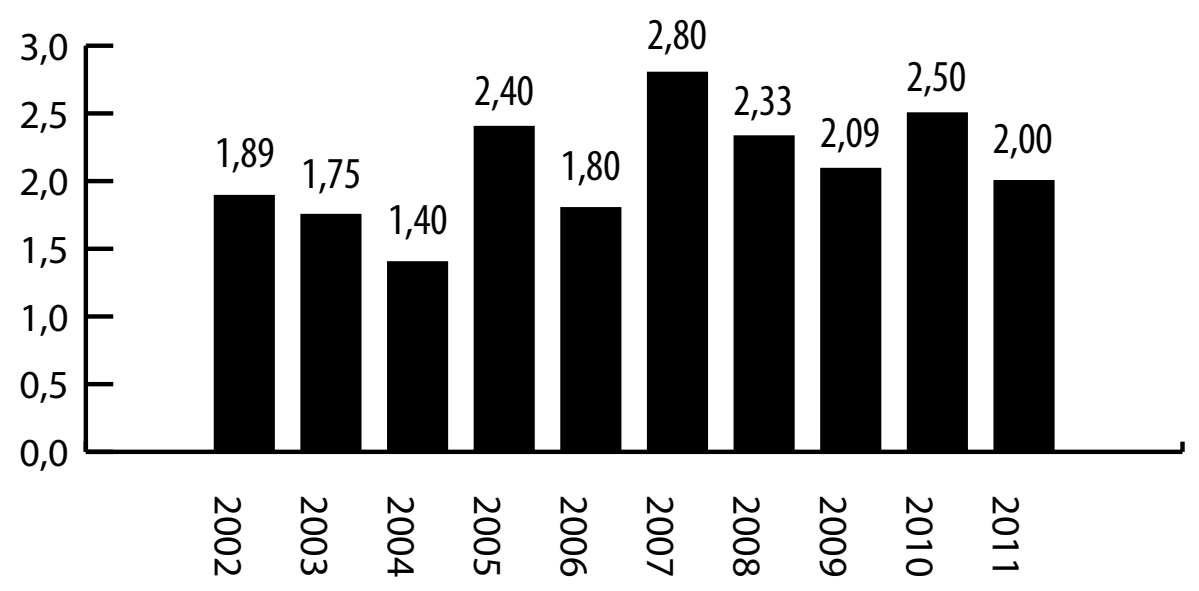

A média com maior número de autores por artigo foi no ano de 2007, isto configura o crescimento de parcerias nas publicações já evidenciado no Gráfico 2. Ainda analisando o Gráfico 2, observa-se que depois de 2007, a média de autores por artigo foi sempre acima de dois ou igual a dois (em 20II). Tal informação reforça e enfatiza que os autores buscam publicar em parceria não somente para dividir esforços, mas em especial para otimizar e disseminar seus estudos de maneira mais rápida e com qualidade, impactando com isso na evolução de determinada área do conhecimento, campo de estudo ou assunto na estrutura intelectual da literatura acadêmica.

\section{AUTORES MAIS PROLÍFEROS}

O Gráfico 4 apresenta os autores que mais artigos publicaram durante o período. 
Gráfico 4 Autores que mais publicaram

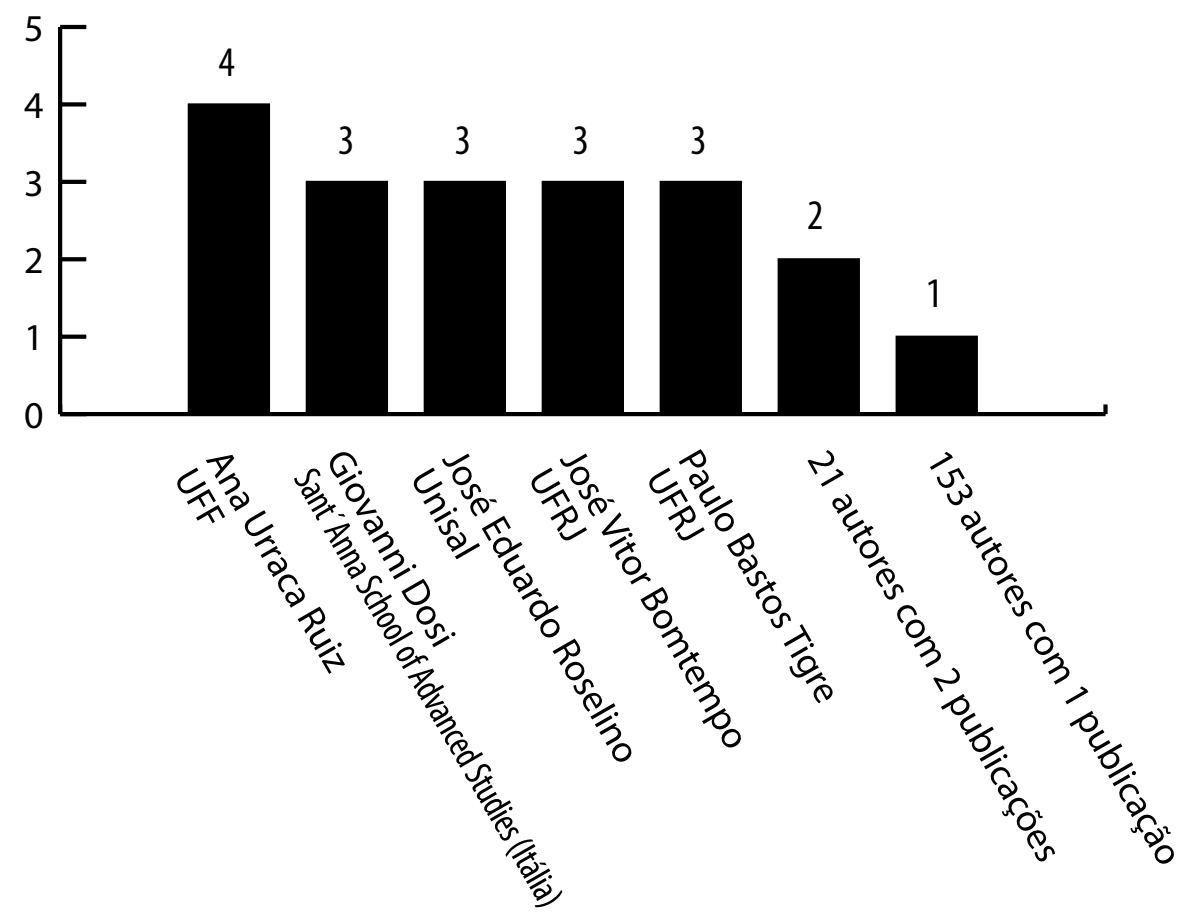

O Gráfico 4 contempla Ana Urraca Ruiz como a autora que mais publicou artigos na Revista Brasileira de Inovação no período analisado, ou seja, quatro publicações. Ainda cabe mencionar os autores Giovanni Dosi, José Eduardo Roselino, José Vitor Bomtempo e Paulo Bastos Tigre, todos com três artigos publicados.

Ainda destacando o Gráfico 4, verifica-se que somente cinco autores publicaram de três a quatro artigos; 2I pesquisadores publicaram dois trabalhos; e a grande maioria, ou seja, I53 autores, teve uma publicação o que equivale a, aproximadamente, $85 \%$ do total de i79 autores que publicaram artigos na referida revista na temporalidade de dez anos. Pode-se fazer uma 
relação com Lei de Lotka, na medida em que esta evidencia que poucos pesquisadores publicam muito e muitos pesquisadores publicam pouco.

A autora Ruiz publicou seus dois primeiros estudos individuais nos anos de 2005 e 2007, os outros dois artigos foram em parceria; em 2009 publicou com o autor Campos e em 2010 com o pesquisador Bhawan. Já o autor Dosi publicou dois artigos em 2002 em parceria com Corlat; e em 2007, em parceria com Cimoli, Nelson e Stiglitz; Roselino em 2006 sozinho e no mesmo ano com Diegues; em 2or publicou novamente com Diegues; Bomtempo, em 2005, publicou com Alves e Coutinho; em 2006, com Dunhan e Almeida; em 2oro, com Dunham e Fleck; 2; Tigre, em 2003, publicou com Dedrick; em 2005 publicou sozinho, em 2007, com Andrade; Silva, Moura, Silva, Oliveira e Souza. É importante salientar que o pesquisador Giovanni Dosi é o único estrangeiro (dentre os autores mais profícuos) sendo da IES Sant'Anna School of Advanced Studies da Itália. Isso evidencia a preocupação da revista investigada abrir portas e socialização suas publicações não apenas em âmbito nacional, mas também, no cenário internacional, ou seja, agregando assim valor ao referido periódico no contexto da estrutura intelectual do tema inovação no Brasil.

O Quadro I, complementa as informações evidenciadas no Gráfico 4, ao evidenciar as áreas de atuação respectivas dos autores mais profícuos da revista RBI.

Quadro I Áreas de atuação dos autores mais profícuos

\begin{tabular}{|ll|}
\hline Autores & Áreas de atuação \\
\hline Giovanni Dosi & Mudança Tecnológica \\
& Economia Industrial \\
& Economia de Inovação \\
& Mudança Tecnológica \\
& Organização Industrial \\
& Dinâmica Industrial \\
\hline José Eduardo Roselino & Economia Industrial \\
& Mudança Tecnológica \\
& Organização Industrial e Estudos Industriais \\
& História do Pensamento Econômico
\end{tabular}




\begin{tabular}{|ll|}
\hline Autores & Áreas de atuação \\
\hline José Vitor Bomtempo & $\begin{array}{l}\text { Organização Industrial e Estudos Industriais } \\
\text { Mudança Tecnológica } \\
\text { Gestão Tecnológica } \\
\text { Economia de Tecnologia }\end{array}$ \\
\hline Paulo Bastos Tigre & $\begin{array}{l}\text { Economia Industrial } \\
\text { Organização Industrial e Estudos Industriais } \\
\text { Mudança Tecnológica }\end{array}$ \\
\hline
\end{tabular}

Ao verificar o Quadro I, é constado que os temas: industrial, tecnologia, organização, economia e mudança, são os mais predominantes em nas áreas de atuação dos cinco autores mais profícuos na RBI. De maneira ampla, tais temáticas confirmam ou refletem os temas mais abordados (Tabela I) nos Ioo artigos investigados.

Remete ao foco (áreas de estudo) que a revista ora pesquisada se dedica para publicação de seus artigos, que são: economia industrial, economia da tecnologia, mudança tecnológica e organizacional, economia e sociologia da inovação, ciência, tecnologia e relação de trabalho, gestão da inovação, políticas de ciência, tecnologia e inovação, história da ciência e da tecnologia (RBI, 2012).

\section{REDES DE COAUTORIA}

A Figura I apresenta as redes de coautoria dos I79 nos Ioo artigos publicados durante o período de 2002 a 201 da Revista Brasileira de Inovação. 
10 ANOS DE PESQUISA DA REVISTA BRASILEIRA DE INOVAÇÃO SOB A ÓTICA DA BIBLIOMETRIA E DA REDE SOCIAL

Figura I Redes de coautoria

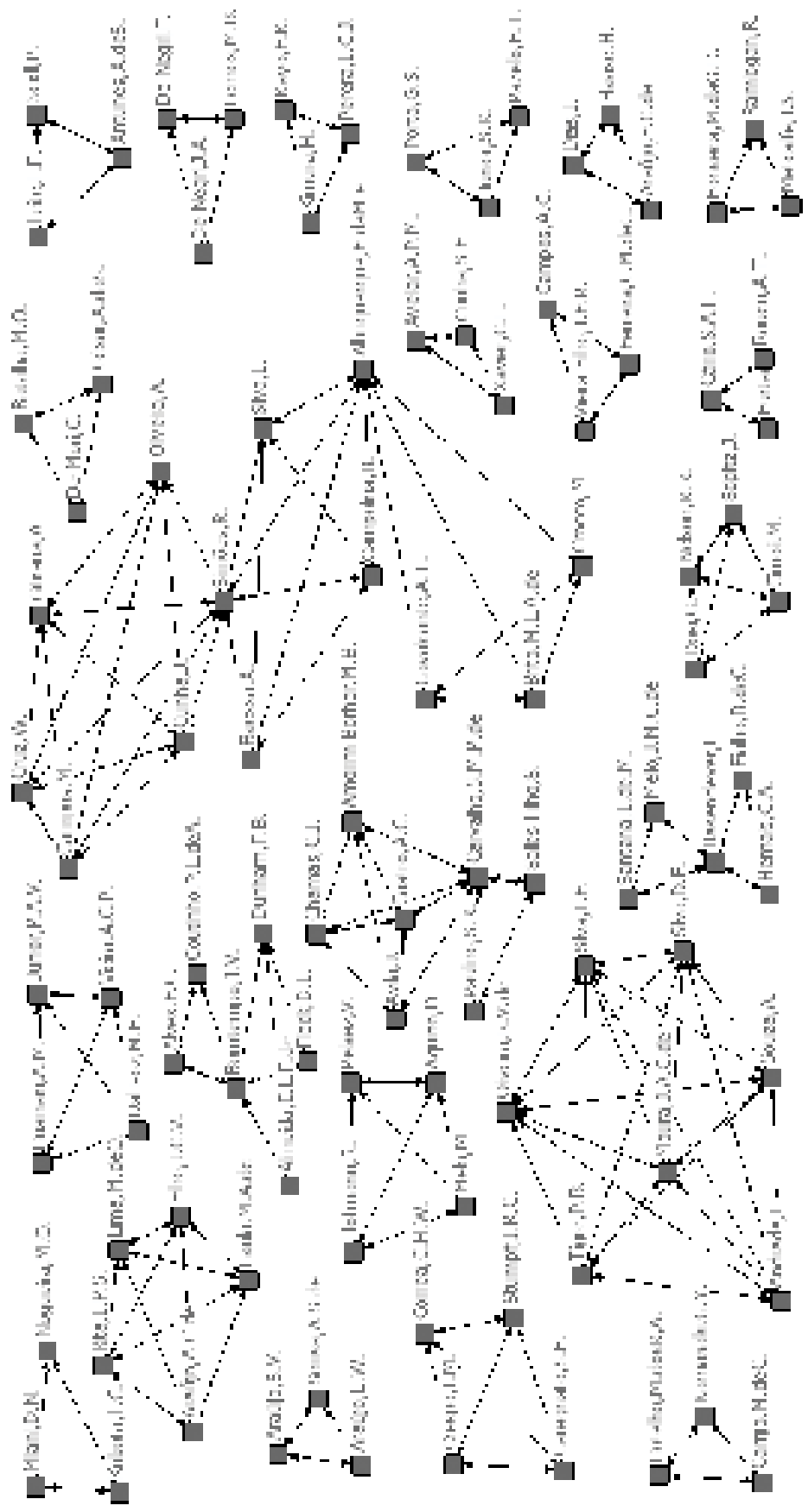


A Figura I apresenta a rede social dos autores, que se configura com baixa interação. Isto é confirmado quando se constata que a densidade total do grupo é de o,oI20, ou seja, a rede realiza I,20\% do total de suas relações. Tal panorama não é o ideal de interação entre os autores, pois, o essencial é ocorrer o maior intercâmbio possível, isto é, trocas de suportes sociais necessárias entre os pesquisadores.

A baixa integração entre os autores pode ser decorrente também do pouco tempo do periódico ora estudado, no que tange a publicações de artigos científicos (apenas dez anos), impactando, direta ou indiretamente, na densidade da rede dos pesquisadores e, consequentemente, de suas respectivas IES.

As evidências de coautoria consolidadas em grupos mostram que as parcerias se mantêm em redes definidas entre três a I3 parceiros, por grupos. As principais parcerias são: (Cruz, W., Campos, M., Gitirana, A., Cunha, J., Oliveira, A., Simões, R., Baessa, A., Silva, L., Campolina, B., Albuquerque, E. da M. E., Cavalcante, A. T., Brito, M. L. A. de, Crocco, M.); (Oliveira, R. V. de, Tigre, P. B., Silva, L. F., Moura, J. A. C. de, Andrade, E., Souza, A. e Silva, D. F.); e (Chamas, C. I., Avila, J., Amorim-Borher, M. B., Castro, A. C., Paulino, S. R., Carvalho, S. M. P. de, Salles-Filho, S.).

Ainda analisando a Figura I, destacam-se os pesquisadores, Albuquerque, E. da M. E. e Simões, R., pois, eles fazem conexões entre grupos menores da maior rede destacada no paragrafo anterior, ou seja, a rede de 13 pesquisadores. É importante salientar que apesar destes autores destacaremse nesta rede, eles não aparecem como mais profícuos deste estudo, pois, ambos publicaram apenas dois artigos cada, porém, estas duas publicações de ambos, foram essenciais para que eles ficassem em evidência, pelo motivo de fazer interações e pontes de conhecimento com outros grupos de pesquisadores, impactando no surgimento da rede de 13 articulistas na Figura I.

Realça-se também que Albuquerque e Simões, são da Universidade Federal de Minas Gerais (UFMG). Ajudando com isso no destaque desta IES na produção de artigos na revista ora estudada, como é confirmado no Gráfico 6. 


\section{REFERENCIAS MAIS CITADAS}

O Gráfico 5 apresenta a frequência dos pesquisadores mais citados nos 100 artigos publicados no periódico ora investigado.

Gráfico 5 Autores mais citados

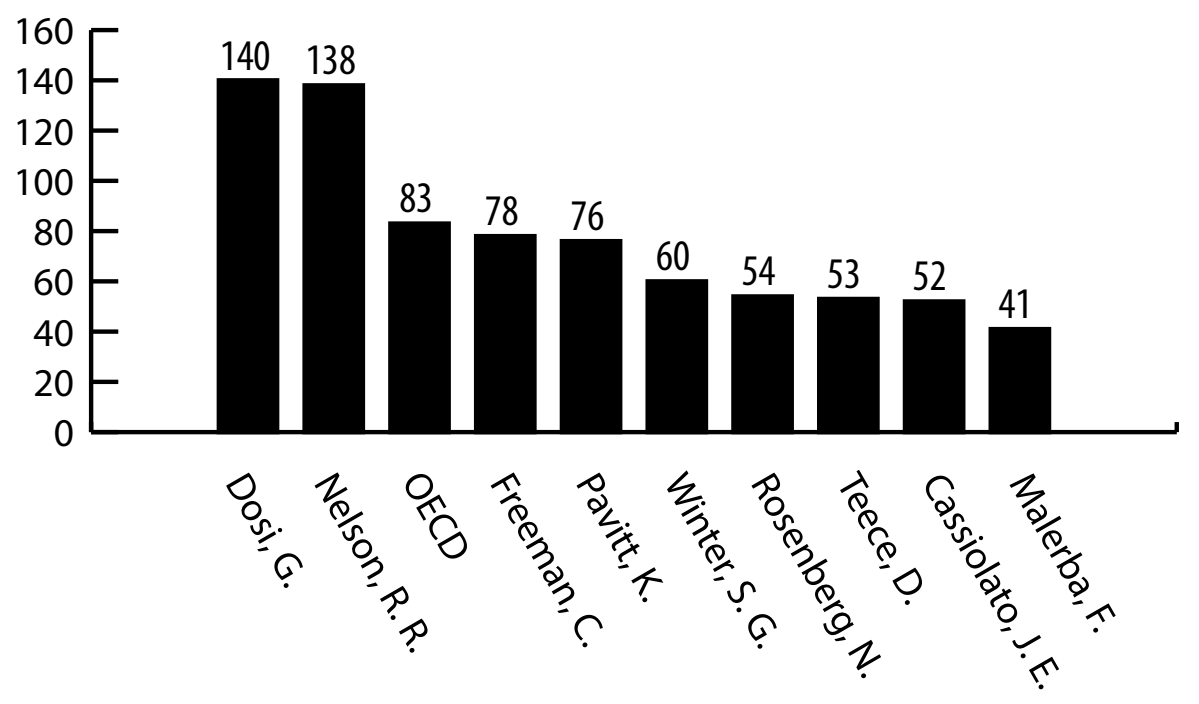

O Gráfico 5 evidencia o autor Giovanni Dosi como o mais citado nas referências, com 140 citações. Em seguida, é contemplado o autor Nelson, R. R., com I38 citações nos Ioo artigos investigados.

Contemplam-se também, outros autores que mais foram citados nas referências dos roo artigos pesquisados, são eles: Freeman, C., Pavitt, K., Winter, S. G., Rosenberg, N., Teece, D., Cassiolato, J. E. e Malerba, F., com $78,76,60,54,53,52$ e 4 I citações respectivamente. Novamente, tais dados remetem a Lei de Lotka.

A Organisation for Economic Co-Operation and Development (OECD) foi citada 83 vezes, evidenciando o fórum responsável pela edição do Manual do Oslo, que dissemina os resultados dos levantamentos estatísticos e das pesquisas da organização sobre questões econômicas, sociais e ambientais, assim 
como convenções, diretrizes e padrões acordados por seus membros (OCDE, 2005). Já em sua terceira edição, traça as diretrizes para coleta e interpretação de dados sobre inovação.

O Quadro 2 complementa as informações evidenciadas no Gráfico 5, contemplando as obras mais citadas nos roo artigos investigados na RBI.

\section{Quadro 2 Obras mais citadas}

DOSI, G. Technological paradigms and technological trajectories: a suggested interpretation of the determinants and directions of technical change. Research Policy, v. 11, n. 3, p. 147-162, 1982.

NELSON, R.; ROSENBERG, N. Technical innovation and national system. In: NELSON, R. National innovation systems: a comparative analysis. Oxford University Press, 1993.

Manual de Oslo (1997).

FREEMAN, C. The Economics of Industrial Innovation. London: Pinter, 2.ed., 1982.

PAVITT, K. Sectoral patterns of technical changes: towards a taxonomy and a theory. Research Policy, v. 13, n. 6, p. 343-373, 1984.

NELSON, R. R.; WINTER, S. An Evolutionary Theory of Economic Change. Cambridge, Mass: Harvard University Press, 1982.

TEECE, D.; PISANO, G.; SHUEN, A. Dynamic capabilities and strategic management. Strategic Management Journal, v. 18, n. 7, p. 509-533, 1997.

CASSIOLATO, J.E.; LASTRES, H.M.M. (Orgs.). Globalização e inovação localizada: experiências de sistemas locais no Mercosul, Brasília: IBICT/MCT, 1996.

Observa-se certo equilíbrio nas obras citadas, no que tange a livros e artigos. Além disso, entre as principais obras citadas, verifica-se uma inerência que ficou evidenciada no Quadro I, no que se refere as áreas de atuação dos principais autores e com as áreas de estudo que a Revista Brasileira de Inovação costuma trabalhar. Destas obras, a maioria das referências mais citadas trata-se de clássicos e obras seminais, o que é interessante e importante para a construção do campo do conhecimento inovação. Tal dado é salutar, pois, enfatiza a preocupação dos autores em citar pesquisadores legitimados na academia internacional, fazendo com que os estudos destes articulistas publicados na RBI tornem-se de maior qualidade, impactando em análises e discussões teoricamente mais bem embasadas e robustas. 


\section{IES MAIS PROFÍCUAS}

O Gráfico 6 apresenta as oito IEs com maior volume de publicações na Revista Brasileira de Inovação, de um total de 5I IES.

A análise do Gráfico 6 evidencia a Universidade Federal do Rio de Janeiro (UfRJ) como a IEs que mais publicou na Revista Brasileira de Inovação, com 20 publicações; seguida de perto pela Universidade Estadual de Campinas (Unicamp) com I3 artigos. Realça-se que a R вI é uma revista da Unicamp, e diante do dado evidenciado no Gráfico 6, enfatiza-se uma endogenia, sendo que isto não é um artifício desejável (CADORE; ANDRADE, 2007), contudo, a endogenia na RBI não é tão robusta, pois, o próprio periódico contempla a abertura para novas IES, influenciando na origem de estudos em nível institucional, regional, nacional e internacional (BANDEIRA, 2008), como pode ser confirmado neste estudo.

Gráfico 6 IES com maior publicação

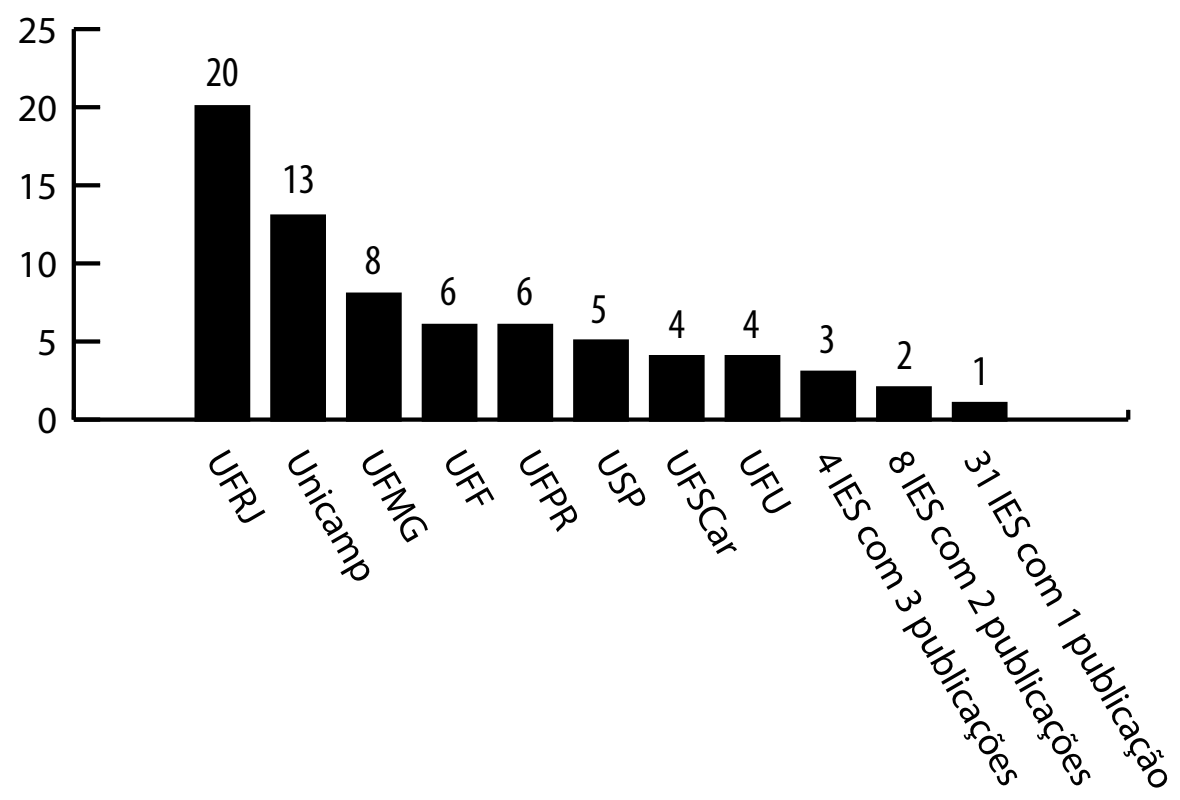


Vale ressaltar as IES UfMG (oito), UfF (seis), UfPR (seis), usP (cinco), UfSCar (quatro) e UFu (quatro) com publicações nos roo artigos investigados. Das 5I IES investigadas nos roo artigos da revista ora estudada, oito instituições publicaram de quatro a 20 artigos; quatro IEs contribuíram com três publicações; oito instituições publicaram duas vezes; e a maioria, ou seja, 3I IES, uma vez somente, ou seja, 60,78\%.

\section{REDE DAS IES}

A Figura 2 apresenta a rede social das 5I IES deste estudo, representando também os Ioo artigos publicados durante o período de dez anos da Revista Brasileira de Inovação.

Observa-se uma centralidade da rede das IEs. Esta centralidade é concentrada principalmente em três IES, são elas: UFRJ, Unicamp e UFMG. Este resultado remete ao contemplado no Gráfico 6, ou seja, estas IES além de serem as que mais publicam no periódico ora pesquisado, são também as mais centrais nos Ioo artigos explorados. A centralidade é confirmada quando se mensura a densidade da rede destas IES, que mostra 0,0227 , ou seja, somente $2,27 \%$ do potencial das interações estão sendo realizadas. O predomínio da UfRJ é confirmada pelo Gráfico 4, por meio dos autores mais prolíferos José Vitor Bomtempo e Paulo Bastos Tigre, ambos desta universidade.

Novamente se verifica a importância da UfRJ, ao visualizar que esta IES publica não apenas com outras IEs do âmbito nacional, mas também com instituições acadêmicas do exterior, sobretudo, com a dos países Inglaterra e Estados Unidos da América (EUA). Este achado se faz importante, pois, salienta a preocupação desta IES com o crescimento de suas pesquisas no contexto da inovação, por meio de parcerias com IEs estrangeiras. 
Figura 2 Rede das IES

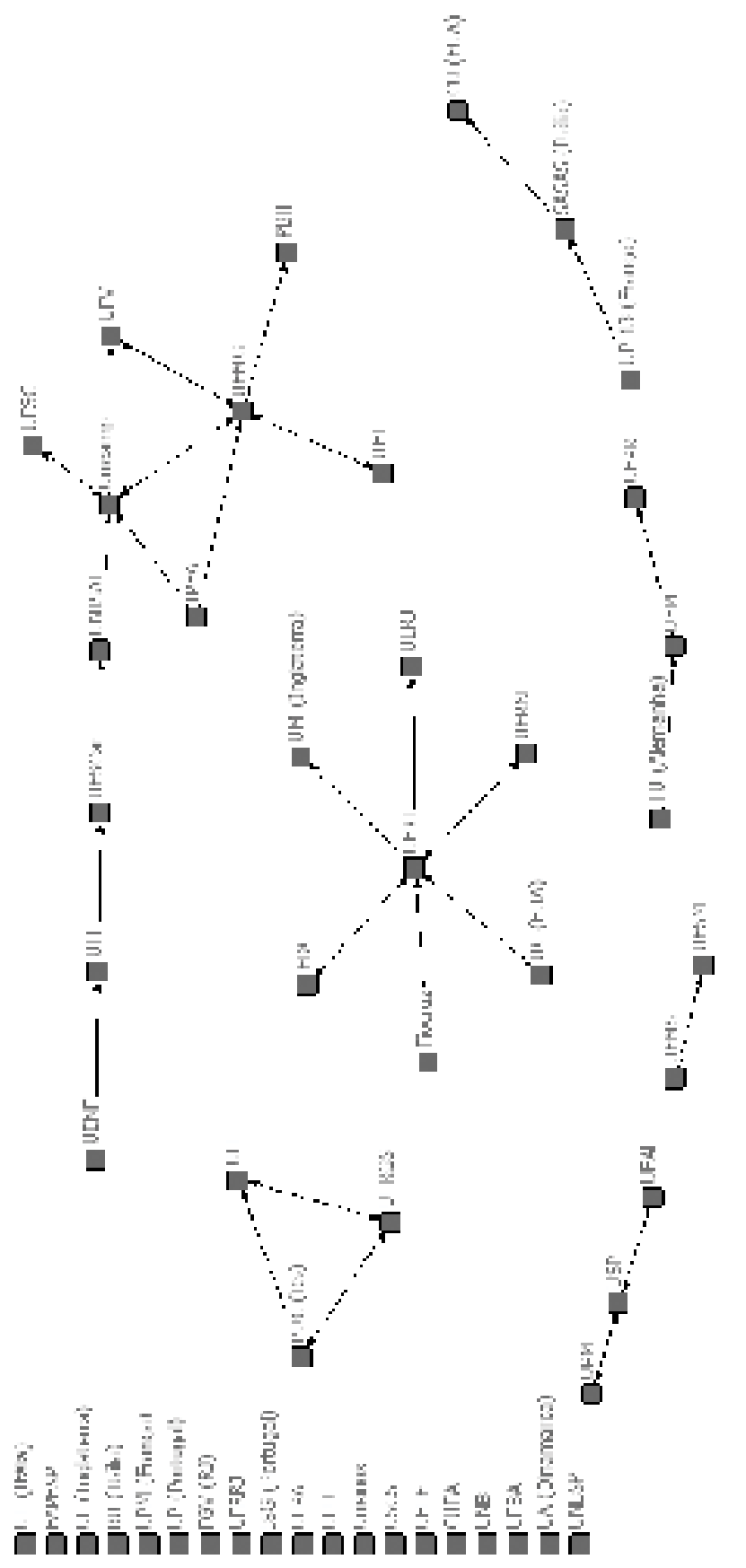


Uma possível explicação para a referida centralidade das IEs é que os autores tendem a publicar, em sua maioria, em parceria, sendo, portanto, estes autores são essenciais para manter laços e interações com outros pesquisadores, influenciando com isso a importância destes articulistas na composição das redes sociais, sendo considerados, os autores principais das redes por serem centrais, impactando a posteriori na robustez destas IEs, em particular a UFRJ na rede da Figura 2.

\section{ABORDAGENS METODOLÓGICAS}

O Gráfico 7 evidencia as abordagens de pesquisa usadas nos Ioo artigos analisados.

Gráfico 7 Abordagens metodológicas

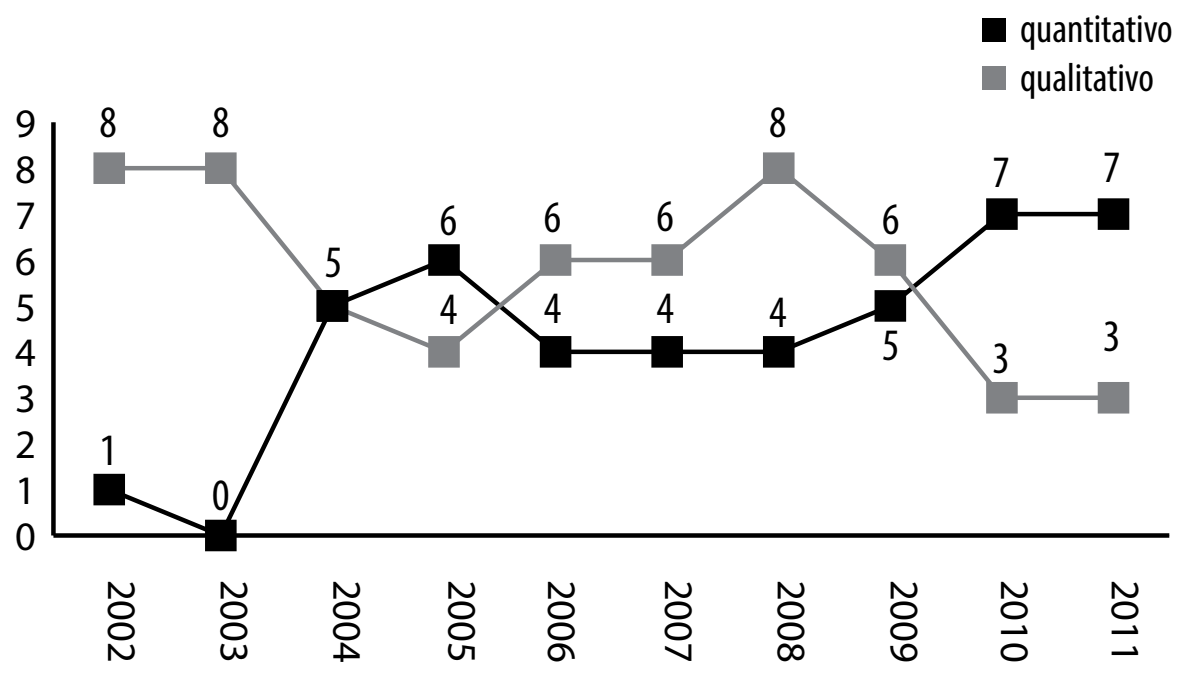

Dos Ioo artigos analisados, 43 deles usam a abordagem quantitativa como o principal método de pesquisa, mostrando uma predominância nos anos de 2005, 20I0 e 20II. Já o método qualitativo apareceu em 57 artigos e predominou na maioria dos anos, com um pico em 2002, 2003 e 2008. No Gráfico 7, verifica-se a alternância na escolha dos métodos qualitativo e 
quantitativo. Em seu estudo, os autores Kneipp et al. (20II) identificaram a abordagem qualitativa como predominante.

Complementando o Gráfico 7, contempla-se a seguir a Figura 3, que evidencia e aprofunda os principais métodos e ferramentas de pesquisa usadas pelos pesquisadores nos Ioo artigos identificados neste trabalho.

Figura 3 Frequência dos principais métodos e ferramentas de pesquisa

\section{estatísticadescritiva döcumental - entrevistasbibliográfica}

Ao analisar a Figura 3, observa-se uma predominância nos tipos de pesquisa documental e bibliográfica. A pesquisa documental remete a dados secundários que foram considerados mais vinculados com as pesquisas de abordagem quantitativa. No que tange a tipologia bibliográfica, verificou-se sua inerência com a abordagem qualitativa, ou seja, artigos que aprofundaram revisões teóricas.

Constata-se também o estudo de caso como um dos métodos de estudo mais visto nos 100 artigos investigados. Quanto às ferramentas de coleta de dados, observou-se um equilíbrio entre as técnicas de entrevistas e questionários. Tal fato remete ao equilíbrio também das abordagens qualitativa e quantitativa no referido estudo. E nesta última, nota-se que a estatística descritiva foi dominante nos trabalhos ora investigados. 


\section{FREQUENNCIA DE PALAVRAS-CHAVE}

A Figura 4 contempla a frequência palavras-chave mais citadas nos Ioo artigos da Revista Brasileira de Inovação de 2000 a 2011.

Destacam-se as palavras-chave: inovação, tecnológica, desenvolvimento, indústria, tecnologia, propriedade, conhecimento, política, entre outras. Estas palavras refletem, de alguma forma, o contexto dos estudos, evidenciando uma relação enfática e imbricada entre as palavras que configuram as relações das palavras-chave com inovação, nas edições da Revista Brasileira de Inovação.

Figura 4 Frequência de palavras-chave

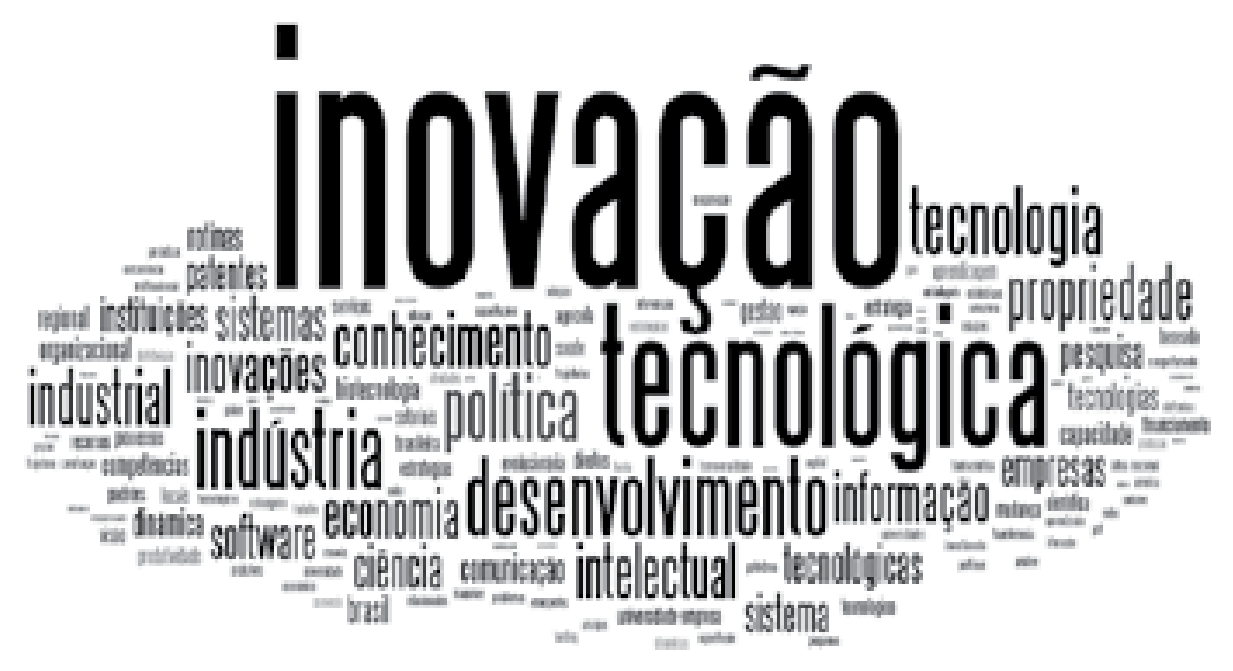

Neste contexto, observa-se a Lei de Zipf, que calcula a frequência de ocorrências das palavras, com o intuito de criar e evidenciar o tema científico que é mais visualizado nos artigos científicos (RIBEIRO; CIRANI; FREITAS, 20I3).

\section{ÁREAS DE ESTUDO}

A análise das áreas de estudo é vista como fator importante para continuidade 
das pesquisas, proporcionando um norte para pesquisadores experientes e, principalmente, para os iniciantes, o que influencia tanto no crescimento quanto na disseminação de futuras pesquisas.

Com o propósito de servir ao debate acadêmico e institucional sobre o tema inovação (RBI, 20I2), foi elaborada a Tabela I, de acordo com as áreas de estudo da RBI, contempladas nas Políticas Editoriais/Foco e Escopo, que são: economia industrial; economia da tecnologia; mudança tecnológica e organizacional; economia e sociologia da inovação; ciência, tecnologia e relação de trabalho; gestão da inovação; políticas de ciência, tecnologia e inovação; e história da ciência e da tecnologia.

Tabela I Áreas de estudo

\begin{tabular}{|c|c|c|c|c|c|c|c|c|c|c|c|}
\hline Temas & 옹 & 응 & 웅 & 은 & 웅 & 웅 & 웅 & 웅 & 웅 & 울 & $\begin{array}{l}\text { o- } \\
\stackrel{8}{2}\end{array}$ \\
\hline Políticas de ciência, tecnologia e inovação & 3 & 2 & 2 & 2 & 2 & 2 & 1 & 1 & 2 & 2 & 19 \\
\hline Gestão da inovação & 1 & 2 & 2 & 2 & & 2 & 3 & 2 & 2 & 2 & 18 \\
\hline Mudança tecnológica e organizacional & & 2 & & 2 & 4 & 2 & & 3 & 2 & 1 & 16 \\
\hline História da ciência e da tecnologia & 2 & 1 & 1 & 2 & 1 & 1 & 1 & 1 & 1 & 1 & 12 \\
\hline Ciência, tecnologia e relação de trabalho & 2 & & 1 & & & 2 & 4 & 1 & 1 & & 11 \\
\hline Economia da tecnologia & & 1 & 1 & 1 & 2 & & 1 & & & 3 & 9 \\
\hline Economia e sociologia da inovação & & & 2 & 1 & 1 & 1 & & 1 & 1 & 1 & 8 \\
\hline Economia industrial & 1 & & 1 & & & & 2 & 2 & 1 & & 7 \\
\hline Total & 9 & 8 & 10 & 10 & 10 & 10 & 12 & 11 & 10 & 10 & 100 \\
\hline
\end{tabular}

Ao analisar a Tabela I, constatou-se que as áreas de estudo que se destacaram foram: políticas de ciência, tecnologia e inovação, gestão da inovação e mudança tecnológica e organizacional, com 19, I8 e 16 artigos publicados, respectivamente, em dez anos de pesquisa, retratando assim $53 \%$ do total de todas as áreas de estudo, de acordo com o foco e escopo da Revista Brasileira de Inovação. Ainda no que tange as áreas de estudo mais prolíferas, verifica-se sua inerência nos temas mais estudados pelos autores que mais publicaram artigos na revista ora investigada. Os temas foram: industrial, tecnologia, organização, economia e mudança. 
As demais áreas de estudo, como: história da ciência e da tecnologia (com I2 artigos publicados), ciência, tecnologia e relação de trabalho (II), economia da tecnologia (nove), economia e sociologia da inovação (oito) e economia industrial (sete artigos publicados). As informações evidenciadas na Tabela I vão ao encontro do que foi contemplado no estudo dos pesquisadores Ribeiro, Cirani e Freitas (2013), os quais estudaram as temáticas publicadas na RAI de 2006 a 2012. 


\section{CONSIDERAÇÕES FINAIS}

Este trabalho explorou a produção científica da Revista Brasileira de Inovação no período de 2002 a 20II. Para tanto, efetuou-se uma análise bibliométrica e de rede social em um universo de Ioo artigos. Foi priorizado na pesquisa o foco nos seguintes critérios: (I) autoria; (II) autores mais prolíferos; (III) redes de coautoria; (IV) referências mais citadas; (v) IES mais profícuas; (VI) rede das IEs; (VII) abordagens metodológicas; (VIII) frequência de palavras-chave; e (Ix) áreas de estudo.

Houve uma prevalência do número de artigos publicados com dois a sete autores, representando $62 \%$ do total de Ioo artigos. Após 2005, verificouse que houve uma ampliação, o que significa o inicio da consolidação de grupos de pesquisa que estudam o tema inovação nos seus vários aspectos, conforme as principais palavras-chave: inovação, tecnológica, desenvolvimento, indústria, tecnologia, propriedade, conhecimento. Esta predominância de autores publicando em parceria, não é inerente a RBI, mas sim, é um fato que vem sendo regular em outras publicações do gênero, como, por exemplo, o paper dos autores Ribeiro, Cirani e Freitas (20I3), que mostra a proeminência de artigos publicados em parceria, na Revista de Administração e Inovação (RAI).

A autora Ana Urraca Ruiz foi a que mais publicou artigos na RBI no período analisado, ou seja, quatro publicações, seguida dos autores, Dosi, Roselino, Bomtempo e Tigre, todos com três artigos publicados. A baixa integração entre os autores desta pesquisa pode ser decorrente do pouco tempo de vida do periódico ora estudado, no que tange a publicações de artigos científicos (apenas dez anos), o que impacta direta ou indiretamente na densidade da rede dos pesquisadores e, consequentemente, de suas respectivas IEs.

Contempla-se uma centralidade da rede das IEs, concentrada principalmente em três IEs, são elas: Universidade Federal do Rio de Janeiro (UfRJ) como a IES que mais publicou na Revista Brasileira de Inovação, com 20 publicações; seguida de perto pela Universidade Estadual de Campinas (Unicamp), com I3 artigos e a Universidade Federal de Minas Gerais (UFMG), com oito artigos. 
Constatou-se um equilíbrio entre as abordagens qualitativa e quantitativa. Também uma predominância nos tipos de pesquisa documental e bibliográfica. E o estudo de caso como um dos métodos de estudo mais visto nos Ioo artigos investigados. Quanto às ferramentas de coleta de dados, observou-se um equilíbrio entre as técnicas de entrevistas e questionários.

Conclui-se, que o acervo dos Ioo artigos investigados da Revista Brasileira de Inovação, apesar de recente, evidencia de maneira satisfatória a produção acadêmica da área de inovação no Brasil, ajudando, assim, a crescer, difundir e socializar a área, por meio de seus artigos científicos publicados na literatura acadêmica nacional, juntamente, com os artigos bibliométricos já realizados sobre a área de inovação, sobretudo, no paper publicado por Ribeiro, Cirani e Freitas (20I3).

Este estudo contribuiu para uma melhor compreensão de como esta sendo trabalhadas as publicações da área de inovação no Brasil, sob a ótica da RBI, proporcionando uma visão (mesmo que sendo amostral), em especial, das redes de colaboração, das IEs mais profícuas e dos temas mais abordados no campo, influenciando no entendimento do comportamento destas publicações nacionais, podendo, ser útil também para futuras pesquisas de pesquisadores seniores e novos pesquisadores, impactando no crescimento, difusão e divulgação de novos papers sobre o campo do conhecimento inovação.

O fator limitador do artigo foi ter trabalhado apenas na análise de um periódico, ou seja, a RBI, entretanto, salienta-se que o objetivo deste estudo foi alcançado. Diante disso, sugere-se para pesquisas futuras uma análise comparativa do acervo da RBI com outra revista da área de inovação do Brasil e/ou do exterior (por exemplo, em países emergentes), aperfeiçoando as informações contempladas neste estudo. Sugere-se também para futuros trabalhos, que se façam a análise de conteúdo dos ıoo artigos explorados. Outra proposta para futuros trabalhos é o fomento das análises de métodos de pesquisa adotados neste estudo, isto é, uma investigação mais aprofundada do por que (por exemplo) a análise qualitativa foi dominante neste estudo. E por fim, sugere-se um aprofundamento do estudo de redes sociais por meio de outros indicadores, o que aperfeiçoaria os resultados desta pesquisa. 


\section{REFERÊNCIAS}

ALVES, F. C.; BOMTEMPO, J. V.; COUTINHO P. L. de A. Competências para inovar na indústria brasileira. Revista Brasileira de Inovação, v. 4, n. 2, p. 301-327, 2005.

AMORIM-BORHER, M. B.; AVILA, J.; CASTRO, A. C.; CHAMAS, C. I.; PAULINO, $S$. Ensino e pesquisa em propriedade intelectual no Brasil. Revista Brasileira de Inovação, v. 6, n. 2, p. 281-310, 2007.

ANDRADE, J. A. B. de; MUŸLDER, C. F. de. A relevância dos temas inovação e qualidade na pesquisa contábil: um estudo bibliométrico em eventos científicos no Brasil. ABCustos Associação Brasileira de Custos, v. 5, n. 3, p. 43-59, 2010.

BANDEIRA, M. B. Publicações científicas em turismo: Uma análise dos periódicos online no Brasil. Revista de Cultura e Turismo, v. 2, n. 1, p. 1-20, 2008.

BARAÑANO, A. M. Gestão da inovação tecnológica: estudo de cinco PMEs portuguesas. Revista Brasileira de Inovação, v. 4, n. 1, p. 57-96, 2005.

BIGNETTI, L. P. Gestão de tecnologia e inovação: uma análise de autores, vertentes teóricas e estratégias metodológicas predominantes em trabalhos apresentados nos encontros da Anpad. In: EnANPAD, 30., 2006, Salvador. Anais... Salvador: Anpad, 2006.

CADORE, S.; ANDRADE, J. B. de. A contribuição da SBQ à pós-graduação em química. Química Nova, v. 30, n. 6, p. 1435-1438, 2007.

CALLE, G. A. D.; SILVA, E. L. da. Inovação no contexto da sociedade do conhecimento. Revista Textos de la Cibersociedad, n. 8, p. 1-20, 2008.

CASSIOLATO, J. E.; BRITO, J. N. de P.; VARGAS, M. A. Arranjos cooperativos e inovação na indústria brasileira. In: ALMEIDA, P. A. et al. Inovações, padrões tecnológicos e desempenho das firmas industriais brasileiras. Brasília: IPEA, 2005.

CIMOLI, M.; DOSI, G.; NELSON, R. R.; STIGLITZ, J. Instituições e políticas moldando o desenvolvimento industrial: uma nota introdutória. Revista Brasileira de Inovação, v. 6, n. 1, p. 55-85, 2007.

CORIAT, B.; DOSI, G. Problem-solving and coordination-governance: advances in a competence-based perspective on the theory of the firm. Revista Brasileira de Inovação, v. 1, n. 1, p. 49-84, 2002.

COSTA, R. M.; FROEHNER, J.; MARINHO, B. de L.; CHU, C. L. Intersecção entre inovação e propriedade intelectual: uma análise bibliométrica. In: Semead, 14., 2011, São Paulo. Anais... São Paulo: USP, 2011.

FRANCISCO, E. de R. RAE-eletrônica: exploração do acervo à luz da bibliometria, geoanálise e redes sociais. Revista de Administração de Empresas, v. 51, n. 3, p. 280306, 2011.

FREEMAN, C.; SOETE, L. A Economia da inovação industrial. Campinas: Unicamp, 2008. 
GAZDA, E.; QUANDT, C. O. Colaboração interinstitucional em pesquisa no Brasil: tendências em artigos na área de gestão da inovação. RAE Eletrônica, v. 9, n. 2, p. 1-28, 2010.

IBGE - Instituto Brasileiro de Geografia e Estatística. Pesquisa industrial de inovação tecnológica 2000. Rio de Janeiro: IBGE, 2002.

KIMURA, H.; BASSO, L. F. C.; MARTIN, D. M. L. Redes sociais e o marketing de inovações. Revista de Administração Mackenzie, v. 9, n. 1, p. 157-181, 2008.

KNEIPP, J. M.; GOMES, C. M.; ROSA, L. A. B. da; PALMA, E. P. Emergência temática da inovação: uma análise da produção científica brasileira no período de 1997 a 2009. In: Semead, 13., 2001, São Paulo. Anais... São Paulo: USP, 2010.

KNEIPP, J. M.; ROSA, L. A. B. da; BICHUETI, R. S.; MADRUGA, L. R. da R.G.; SCHUCH JÚNIOR, V. F. Emergência temática da inovação sustentável: uma análise da produção científica através da base Web of Science. Revista de Administração da UFSM, v. 4, n. 3, p. 442-457, 2011.

KNEIPP, J. M.; ROSA, L. A. B. de; BICHUETI, R. S.; PERLIN, A. P.; SCHUCH JÚNIOR, V. F. Uma análise da evolução da produção científica sobre inovação no Brasil. Estratégia \& Negócios, v. 4, n. 1, p. 133-157, 2011.

LOPES, A. P. V. B. V.; CARVALHO, M. M. de. Evolução da literatura de inovação em relações de cooperação: um estudo bibliométrico num período de vinte anos. Gestão $\&$ Produção, v.19, n.1, p. 203-217, 2012.

LOPES, D. P. T.; BARBOSA, A. C. Q. Inovação e competências: como esses conceitos são articulados em grandes organizações brasileiras. In: SIMPEP, 8., 2006, Bauru. Anais... Bauru: SIMPEP, 2006.

MACHADO, M. M.; MACHADO, D. D. P. N. Análise da produção científica de periódicos nacionais que tratam dos temas inovação e estratégia. In SIMPOI, 15, 2012, São Paulo. Anais... São Paulo: FGV-EAESP, 2012.

MACIAS-CHAPULA, C. A. O papel da informetria e da cienciometria e sua perspectiva nacional e internacional. Ciência da Informação, v. 27, n. 2, p. 134-140, 1998.

MARION FILHO, P. J.; SONAGLIA, C. M. Inovações tecnológicas na indústria de móveis: uma avaliação a partir da concentração produtiva de Bento Gonçalves (RS).

Revista Brasileira de Inovação, v. 9, n. 1, p. 93-118, 2010.

MATHEUS, R. F.; VANZ, S. A. de S.; MOURA, A. M. M. de. Coautoria e coinvenção: indicadores da colaboração em CT\&I no Brasil. Disponível em: $<$ http://www. rfmatheus.com.br/doc/matheusvanzmoura-coinvencao-2007.pdf $>$. Acesso em 24/07/2012.

METCALFE, J. S. Equilibrium and evolutionary foundations of competition and technology policy: new perspectives on the division of labour and the innovation process. Revista Brasileira de Inovação, v. 2, n. 1, p. 111-146, 2003.

MUŸLDER, C. F. de. Inovação e arranjos produtivos locais: uma análise bibliométrica 
da produção da área de administração brasileira. Amazônia, Organizações e Sustentabilidade, v. 1, n. 1, p. 119-132, 2012.

MUŸLDER, C. F. de; ROCHA, A. M.; GONÇALVES, C. M.; SOUZA, R. B. de; OLIVEIRA, W. T. de. Tema inovação: uma análise bibliométrica no evento Enanpad 2007. Revista Gestão \& Tecnologia, v. 8, n. 1, p. 1-13, 2008.

NELSON, R. R. As fontes do crescimento econômico. Campinas: Unicamp, 2006.

OCDE - Organização para a Cooperação e Desenvolvimento Econômico. Manual de Oslo. Paris: Eurostat, 2005.

OCDE - Organização para a Cooperação e Desenvolvimento Econômico. Manual de Oslo. Paris: Eurostat, 2006.

RAMOS-RODRÍGUEZ, A. R.; RUÍZ-NAVARRO, J. Changes in the intellectual structure of strategic management research: a bibliometric study of the strategic management journal, 1980-2000. Strategic Management Journal, v. 25, n.10, p. 9811004, 2004.

RASERA, M.; BALBINOT, Z. Redes de inovação, inovação em redes e inovação aberta: um estudo bibliográfico e bibliométrico da produção científica no Enanpad 2005-2009 sobre inovação associada a redes. Análise, v. 21, n. 2, p. 127-136, 2010.

RASERA, M.; CHEROBIM, A. P. M. S. Investimentos em tecnologia da informação e inovação: estudo bibliográfico e bibliométrico da produção científica no Enadi 20072009. In: EnANPAD, 34., 2010, Vitória. Anais... Vitória: Anpad, 2010.

RBI - Revista Brasileira de Inovação. Foco e escopo. Disponível em $<\underline{\text { http: } / / w w w . i g e . ~}$ unicamp.br/ojs/index.php/rbi>. Acesso em 08/07/2012.

RIBEIRO, H. C. M.; CIRANI, C. B. S.; FREITAS, E. J. da S. M. de. Análise da produção científica da Revista de Administração e Inovação. Revista de Administração e Inovação, v. 10, n. 4, p. 208-228, 2013.

RUIZ, A. U.; BHAWAN, R. Diferenças de comportamento inovador entre empresas nacionais e estrangeiras no Brasil. Revista Brasileira de Inovação, v.9, n.1, p. 29-68, 2010.

SANTANA, L. M. de; HASENCLEVER, L.; MELLO, J. M. C. de. Capacitação tecnológica e competitividade na petroquímica brasileira nos anos 1990: o caso de Camaçari-BA. Revista Brasileira de Inovação, v. 2, n. 1, p. 147-177, 2003.

SANTOS, J. L. S.; URIONA-MALDONADO, M.; SANTOS, R. N. M. dos. Inovação e conhecimento organizacional: um mapeamento bibliométrico das publicações científicas até 2009. Organizações em Contexto, v. 7, n. 13, p. 31-58, 2011.

SAQUETTO, T. C.; CARNEIRO, T. C. J. Inovação tecnológica: análise da publicação científica de 2001 a 2010. Análise, v.22, n 1, p.17-30, 2011.

SCARPIN, M. R. S.; GOMES, G.; MACHADO, D. D. P. N. Produção científica sobre inovação em periódicos de alto impacto - 2006/2010: uma análise sob a ótica das redes sociais. In: EnANPAD, 35., 2011, Rio de Janeiro. Anais... Rio de Janeiro: Anpad, 2011. 
TÁLAMO, J. R.; CARVALHO, M. M. de. Redes de cooperação com foco em inovação: um estudo exploratório. Gestão \& Produção, v. 17, n. 4, p. 747-760, 2010.

TIDD, J.; BESSANT, J.; PAVITT, K. Gestão da inovação. Porto Alegre: Bookman, 2008.

TIGRE, P. B. Gestão da inovação: a economia da tecnologia no Brasil. Rio de Janeiro: Campus, 2006.

TIGRE, P. B. Paradigmas tecnológicos e teorias econômicas da firma. Revista Brasileira de Inovação, v. 4, n. 1, p. 187-223, 2005.

TOMAÉL, M. I.; ALCARÁ, A. R.; DI CHIARA, I. G. Das redes sociais à inovação.

Ciência da Informação, v. 34, n. 2, p. 93-104, 2005.

VANTI, N. A. P. Da bibliometria à webometria: uma exploração conceitual dos mecanismos utilizados para medir o registro da informação e a difusão do conhecimento. Ciência da Informação, v. 31, n. 2, p. 152-162, 2002.

YONAMINI, F. M.; GONÇALVES, F. de O. Financiamento do crescimento da indústria brasileira: seriam as fontes adequadas aos regimes tecnológicos setoriais? Revista Brasileira de Inovação, v. 9, n. 1, p. 69-92, 2010. 


\section{DADOS DOS AUTORES}

\section{HENRIQUE CÉSAR MELO RIBEIRO^ hcmribeiro@hotmail.com} Doutor em Administração pela Uninove

Instituição de vinculação: Universidade Nove de Julho

São Paulo/SP - Brasil

Áreas de interesse em pesquisa: Estratégia, Governança Corporativa, Ensino e Pesquisa.

*Loteamento Guará, 23 São Judas Tadeu Parnaíba/PI 64200-970

ROSANY CORRÊA rosanycorrea@hotmail.com

Mestre em Administração pela UESPI

Instituição de vinculação: Universidade Estadual do Piauí

Parnaíba/PI - Brasil

Áreas de interesse em pesquisa: Gestão Ambiental, Sustentabilidade e Conflitos

Socioambientais. 